\title{
Percutaneous transluminal coronary angioplasty in unstable angina: comparison with stable angina
}

\author{
PETER J QUIGLEY, JOHN ERWIN, BRIAN J MAURER, MICHAEL J WALSH, \\ GERARD F GEARTY \\ From the Cardiac Department, Royal City of Dublin Hospital, Dublin, Ireland
}

SUMMARY Percutaneous transluminal coronary angioplasty was performed in 25 patients with unstable angina and in a similar group of 25 patients with stable angina. The frequency of single, double, and triple vessel disease was identical in each group. Technical success was achieved in $22(81 \%)$ out of 27 attempts in those with unstable angina and in $14(52 \%)$ out of 27 attempts in those with stable angina. Vessel occlusion occurred in nine patients, necessitating emergency bypass surgery in four. There was evidence of myocardial infarction in three patients in each group and one patient in the unstable group subsequently died. Twenty eight of 32 successfully treated patients were followed up by means of repeat coronary arteriography, exercise electrocardiography, and clinical assessment after a mean (SD) interval of 14 (7) months. There was angiographic evidence of restenosis in $32 \%$ (seven of 22) of lesions in the unstable group and $44 \%$ (four of nine) of lesions in the stable group. There were no late infarctions or deaths during the follow up period. These results support the growing evidence that angioplasty can be carried out safely and effectively in patients with unstable angina.

The risk of infarction and death is high in patients with unstable angina. ${ }^{1}$ Excluding patients with main stem disease, most studies have shown similar infarct and mortality rates when such patients are treated medically or surgically. ${ }^{23}$ Patients treated medically, however, are more likely to have severe symptoms during follow up and many eventually require operation for relief of incapacitating angina.

Percutaneous transluminal coronary angioplasty is a new treatment of obstructive coronary disease in which a specially designed balloon tipped catheter is introduced through a peripheral artery and inflated across an atherosclerotic plaque to relieve the obstruction. Successful angioplasty can relieve angina and improve objective signs of myocardial ischaemia. ${ }^{4}$ Despite the growing experience worldwide with this technique, little information is available about its suitability in patients presenting with unstable angina. We report the efficacy and long term results of coronary angioplasty combined with medical management in selected patients with this condition.

Requests for reprints to Dr Peter J Quigley, Cardiac Department, King's College Hospital, London SE5 9RS.

Accepted for publication 25 November 1985

\section{Patients and methods}

Between November 1982 and April 1984, 25 patients with unstable angina and a similar group of 25 patients with stable angina presenting to three hospitals were deemed to be suitable for percutaneous transluminal coronary angioplasty. This group constituted $50\left(89^{\circ}\right)$ of the first 56 cases in which angioplasty was performed at our hospital. All patients with unstable angina had experienced either (a) worsening in frequency, severity, or duration of chest pain; or $(b)$ severe episodes of prolonged pain at rest immediately before admission. Angioplasty was performed in these patients during the same hospital admission after initial management by bed rest and medical treatment including nitrates, $\beta$ blockers, and calcium antagonists. Serial electrocardiograms and enzyme estimations were performed to exclude fresh myocardial infarction.

Angiographic indications for angioplasty included high grade ( $>70 \%$ reduction of lumen diameter) accessible lesions in one or more major coronary vessels. Patients with left main stem disease, severe diffuse disease, total vessel occlusion, or involvement of major side branches were considered to be unsuitable as were those who were otherwise unfit 
Table 1 Patient description and results

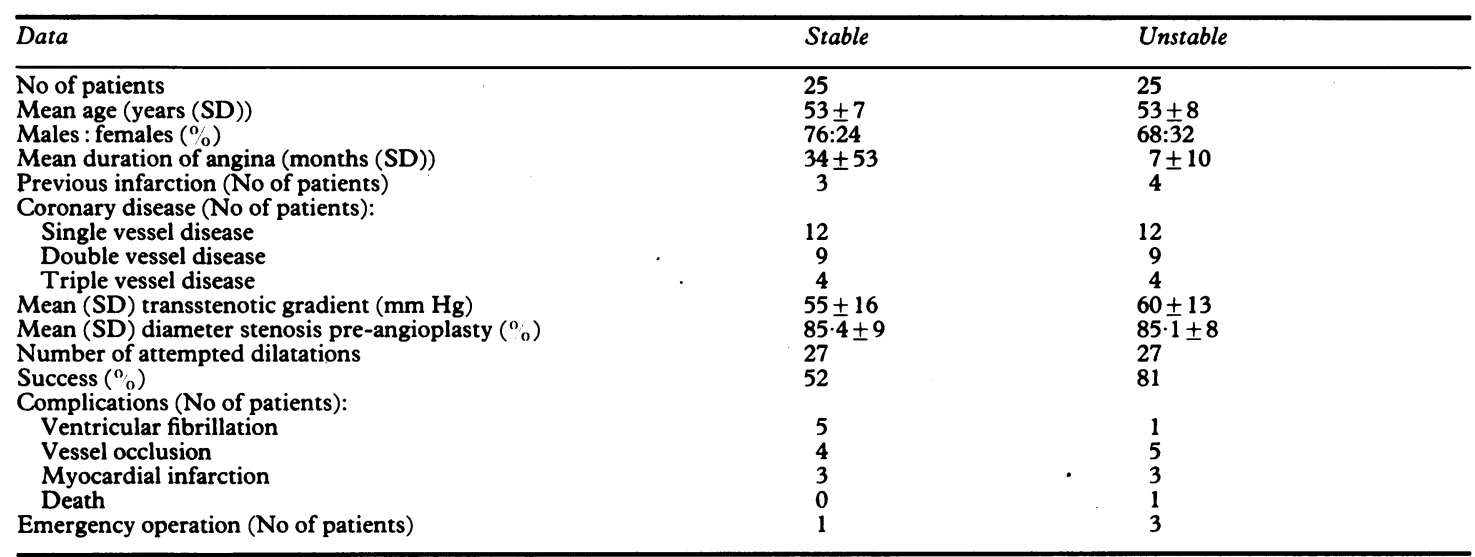

for coronary artery bypass surgery. Informed consent was obtained from all patients after we had discussed their clinical and angiographic data with the cardiac surgeons. Angioplasty was performed as previously described. ${ }^{6}$ All patients received nifedipine $10 \mathrm{mg}$ orally before the procedure. After successful angioplasty heparin (20000 units) was administered by continuous infusion for 24 hours and patients were subsequently discharged on aspirin $300 \mathrm{mg}$ daily for six months.

We analysed and compared results for each group, using the $\chi^{2}$ test where appropriate.

\section{Results}

Twenty seven dilatations were attempted in 25 patients in each group. Table 1 summarises the details. The average interval between admission and angioplasty in patients presenting with unstable angina was 11.5 days (range 1-58 days). A technically successful dilatation, defined as at least a $20 \%$ increase in lumen diameter, was achieved in 14 out of 27 attempts in patients with stable angina and in 22 out of 27 attempts in those with unstable angina. In 32 patients in whom angioplasty was successful, the mean (SD) diameter stenosis was reduced from $84(8 \%)$ to $22(22 \%)$ and the mean transstenotic gradient from $58(13)$ to $17(10) \mathrm{mm}$ $\mathrm{Hg}$ (Fig). Angioplasty was unsuccessful in 18 patients, and this was mainly because severely stenotic segments ( 12 patients) could not be crossed. In three we were unable to approach the stenosis because of vessel tortuosity. After successfully crossing the stenosis in two patients, we were unable to improve the angiographic appearance or appreciably reduce the transstenotic gradient. One patient with unstable angina initially had a successful dilatation of a lesion of the proximal left anterior descending artery but subsequently occlusion of the distal vessel developed; this was presumably due to a dislodged thrombus. Four patients in whom failed angioplasty was associated with clinical deterioration had emergency bypass surgery; two of them had evidence of transmural infarction on subsequent electrocardiograms. Acute vessel occlusion occurred in nine patients and was associated with electrocardiographic and enzyme changes of infarction in five, despite emergency operation in two and repeat angioplasty in another. One patient in whom angioplasty was unsuccessful and uncomplicated had a myocardial infarction 12 hours later and since then

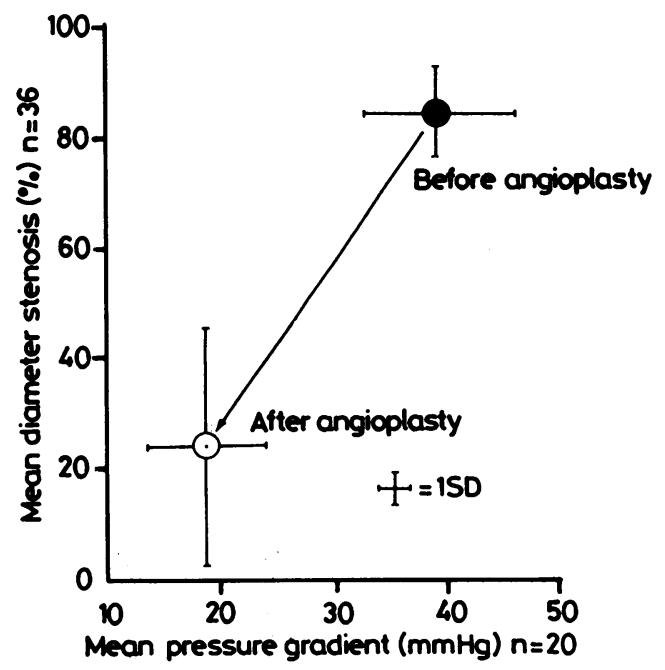

Figure Pressure recordings across coronary stenoses in 36 successful dilatations. 
Table 2 Site of attempted dilatation

\begin{tabular}{lllllll}
\hline Angina & $L A D p$ & $L A D m$ & $R C A p$ & $R C A m$ & Circ & Total \\
\hline Stable & 10 & 12 & 2 & 2 & 1 & 27 \\
Unstable & 15 & 10 & - & 1 & 1 & 27
\end{tabular}

LAD, left anterior descending artery; RCA, right coronary artery; Circ, circumflex coronary artery; p, proximal to first septal perforator (LAD) or first anterior ventricular branch (RCA); m, mid-segment.

has been angina free. In one case failure to cross a mid-segment stenosis of the left anterior descending artery was associated with acute vessel occlusion and what initially appeared"to be a small uncomplicated anterolateral infarct. We decided not to proceed to emergency operation. A week later this patient had an extension of his infarct with recurrent ventricular fibrillation. Progressive clinical deterioration followed and he died of cardiogenic shock and renal failure.

Follow up in 32 of the successfully treated patients ( 20 from the unstable group and 12 from the stable group) included clinical assessment, repeat coronary arteriography (28 patients), and exercise electrocardiography (26 patients). The mean interval between angioplasty and follow up arteriography was 14 (7) months (range 2-28 months). All except one patient, who presented with recurrent unstable angina after two months, were followed for at least five months (Table 3). Restenosis was defined as a loss of $>50 \%$ of the previous gain in luminal diameter. Seven patients in the unstable group complained of chest pain on close questioning; four of them had restenosis. One patient presented with recurrent unstable angina and restenosis within two months and had coronary bypass surgery. Five patients in the stable group had recurrent chest pain, with restenosis in four.

There was angiographic evidence of restenosis in seven $(32 \%)$ of 22 lesions successfully dilated and restudied in the unstable group and in four $(44 \%)$ of nine lesions in the stable group. Three out of 11 patients with restenosis were free of symptoms and eight of them had negative submaximal exercise electrocardiograms. The four patients in the stable group who were not restudied are angina free. There

Table 3 Long term follow up in successfully treated patients

\begin{tabular}{|c|c|c|}
\hline & Stable & . Unstable \\
\hline $\begin{array}{l}\text { No of patients } \\
\text { Mean (SD) interval` (months) } \\
\text { Late deaths } \\
\text { Non-fatal infarction } \\
\text { Recurrent chest pain } \\
\text { Positive exercise test } \\
\text { Restenosis (No of lesions) }\end{array}$ & $\begin{array}{l}8 \\
16(6) \\
0 \\
0 \\
5 \\
1 \\
4\end{array}$ & $\begin{array}{l}20 \\
14(7) \\
0 \\
0 \\
7 \\
4 \\
7\end{array}$ \\
\hline
\end{tabular}

ॠTo repeat arteriography. were no late infarctions or deaths in either group during the follow up period.

\section{Discussion}

The optimal management of patients with unstable angina has been the subject of much discussion over the past 10 years. ${ }^{7}$ A conservative approach may be appropriate when chest pain settles rapidly with medication. ${ }^{8}$ Medical management alone is associated with a considerable risk of subsequent infarction and death, ${ }^{910}$ and a high recurrence rate of severe angina during follow up. Twenty of our patients presented with crescendo angina while five had severe cardiac pain at rest. Ten patients had recurrent episodes of pain in hospital despite bed rest and medical treatment and thus belonged to a high risk subgroup. Mechanical intervention when the coronary pathophysiology is unstable might be expected to be more difficult and possibly more hazardous than in patients with stable angina. Our results suggest that this is not so. The success rate of angioplasty in patients with unstable angina was higher $(81 \%$ vs $52 \%)$ than that in the stable group, while the frequency of serious complications such as vessel occlusion and myocardial infarction was similar in both groups. Table 1 shows that both groups were similar in terms of mean age, previous infarction, extent of coronary disease, and severity of stenosis before angioplasty. From the beginning of our programme the ratio of successful intervention in each group remained the same, implying that increasing experience and technological development do not explain the apparent difference in results. This difference may be explained in several ways. Firstly the frequency of severe stenoses affecting the proximal portion of the left anterior descending artery (Table 2) was higher in patients with unstable angina. This is the ideal site for attempted angioplasty. ${ }^{11}$ These patients had had symptoms for a shorter time, perhaps indicating the presence of a rapidly evolving, soft, distensible lesion which may be associated with plaque rupture or thrombus formation or both. Such a lesion is more likely to allow passage of the balloon catheter and subsequent dilatation. There was evidence of distal embolisation in one patient with unstable 
angina after dilatation of a severe proximal stenosis. This seems to be a rare complication of angioplasty, but not an unexpected one if, as seems likely, fresh thrombus formation plays a part in the pathophysiology. ${ }^{12}$

The two groups comprised a large part ( $89 \%$ ) of our initial experience with this technique. It is likely that with increased experience the success rate in the stable group will rise and the difference between the two groups will become less pronounced, as shown by Meyer $e t$ al in the only other published report in which the efficacy of angioplasty in stable and unstable angina has been compared. ${ }^{13}$

The total, that is, in hospital and late, infarct and mortality rates $(12 \%$ and $4 \%$ respectively) in our patients with unstable angina who underwent angioplasty compare favourably with published results of similar patients treated medically or surgically. ${ }^{23}$ Our results are slightly biased, however, by the fact that two patients had successful emergency bypass surgery without infarction after acute vessel occlusion had occurred during angioplasty. Others have shown similar mortality ${ }^{1415}$ and complication rates when operation and angioplasty are compared, whereas medical treatment alone is associated with recurrence of severe symptoms in $20-40 \%$ of patients during the first year of follow up. ${ }^{2}$ Although on questioning seven $(35 \%)$ of our patients complained of chest pain during follow up, three of them had no evidence of restenosis or important disease elsewhere to account for their symptoms. Angina, when it did recur, was usually mild, that is, grade I-II (New York Heart Association criteria), except for one patient who presented with recurrent unstable angina and required emergency bypass operation.

Exercise electrocardiography was surprisingly unhelpful in identifying those patients with restenosis. This is consistent with the recently reported findings of De Feyter et al ${ }^{16}$ but we cannot account for this finding.

In conclusion, our work supports the observation that urgent coronary angioplasty combined with medical treatment can be performed safely and effectively in patients with unstable angina. In addition the nature of the pathophysiological processes in these patients may make them technically more suitable for this procedure than those with stable angina.

We thank Dr D Hogan for his invaluable help in carrying out this work.

This work was supported by a grant from the Irish Heart Foundation.

\section{References}

1 Gazes PC, Mobley EM, Faris HM, Duncan RC, Humphries GB. Preinfarction (unstable) angina. A prospective study and 10 year follow up. Circulation 1973; 48: 331-6.

2 Russell RO Jr, Moraski RE, Kouchoukos N, et al. Unstable angina pectoris: National Cooperative Study Group to compare surgical and medical therapy. $A m \mathcal{F}$ Cardiol 1978; 42: 839-48.

3 Brown CA, Hutter AM Jr, DeSanctis RW, et al. Prospective study of medical and urgent surgical therapy in randomisable patients with unstable angina pectoris. Am Heart f 1981; 102: 959-64.

4 Cowley MJ, Vetrovec GW, Wolfgang TC. Efficacy of percutaneous transluminal coronary angioplasty. $\mathrm{Am}$ Heart f 1981; 101: 272-80.

5 Williams DO, Riley RS, Singh AK, Gerwitz H, Most AS. Evaluation of the role of coronary angioplasty in patients with unstable angina pectoris. Am Heart $\mathcal{f}$ 1981; 102: 1-9.

6 Gruntzig AR, Senning A, Siegenthaler WE. Nonoperative dilatation of coronary artery stenosis. $N$ Engl f Med 1979; 301: 61-8.

7 Russell RO Jr, Rackley CD, Kouchoukos NT. Unstable angina pectoris; do we know the best management? Am $\mathcal{F}$ Cardiol 1981; 48: 590-1.

8 Mulcahy R, Daly L, Graham I, et al. Unstable angina: natural history and determinants of prognosis. Am $\mathfrak{J}$ Cardiol 1981; 48: 525-8.

9 Braunwald E, Cohn PF. Unstable angina. In: Braunwald $\mathrm{E}$, ed. Heart disease. A textbook of cardiovascular medicine. 2nd ed. Philadelphia: WB Saunders, 1984: 1355-9.

10 Bertolasi CA, Tronge JE, Riccitelli MA, Villamayor RM, Zuffardi E. Natural history of unstable angina with medical or surgical therapy. Chest 1976; 70: 596-605.

11 Kent KM, Bentivoglio LG, Block PL, et al. Percutaneous transluminal coronary angioplasty; report from the registry of the National Heart, Lung and Blood Institute. Am f Cardiol 1982; 49: 2011-20.

12 Vetrovec GW, Cowley MJ, Overton H, Richardson DW. Intracoronary thrombus in syndromes of unstable myocardial ischaemia. Am Heart $\mathcal{F} 1981$; 102: 1202-8.

13 Meyer J, Schmitz H, Kiesslich T, et al. Percutaneous transluminal coronary angioplasty in patients with stable and unstable angina pectoris: analysis of early and late results. Am Heart $\mathcal{f}$ 1983; 106: 973-80.

14 McAllister BD, Hartzler GO, Reed WA, Johnston TW. Coronary angioplasty for unstable angina: comparison with coronary artery bypass surgery [Abstract]. f Am Coll Cardiol 1984; 3: 470.

15 Faxon DP, Detre KM, McGabe CH, et al. Role of percutaneous transluminal coronary angioplasty in the treatment of unstable angina: report from the National Heart, Lung and Blood Institute percutaneous transluminal coronary angioplasty and coronary artery surgery study registries. $A m \mathcal{F}$ Cardiol 1983; 53: $131 \mathrm{c}-5 \mathrm{c}$.

16 De Feyter PJ, Serruys PW, van den Brand M, et al. Emergency coronary angioplasty in refractory unstable angina. $N$ Engl $f$ Med 1985; 313: 342-6. 